\title{
The Race against COVID-19 in the US
}

\author{
Isha Patel ${ }^{*}$, Allyson Goff', Shinae Cho ${ }^{1}$ \\ ${ }^{1}$ Department of Pharmacy Practice, Administration and Research, Marshall University School of Pharmacy, \\ One John Marshall Drive, Huntington, WV 25755, USA \\ ${ }^{2}$ Department of Communication Sciences and Disorders, School of Rehabilitation and Communication \\ Sciences, Ohio University, Athens, OH, 45701, USA
}

COVID-19, an enveloped, positive-sense single-stranded RNA virus, is spreading quickly and growing exponentially world-wide [1]. As of March 27, 2020, in the US, there are 103,321 individuals who have contracted it and 1,246 have died [2]. Despite the US's knowledge of the virus since the end of 2019, lack of sufficient preparation is beginning to prove devastating for the American people. One reason for COVID19 's vigor may be that RNA viruses with spikes on their envelopes have been presumed to have likely outbreak potential due to their high mutation and recombination rate [1]. Coronaviruses can be divided into four types: $\alpha, \beta, \gamma$, and $\delta$, depending on the serotype and genotype. COVID-19 is a $\beta$ coronavirus, which causes infections in humans. The most prevalent symptoms of coronavirus include fever, dry cough, lethargy, and muscle pain. The less common symptoms are sore throat, rhinorrhea, hemoptysis, diarrhea, and chills. About $25 \%$ of confirmed cases can lead to complications, such as Acute Respiratory Distress Syndrome (ARDS), sepsis, and septic shock. Such complications are seen more often in the elderly population with comorbidities [3].

According to public health professionals, the most strategic method to avoid further spread seems to be extensive social distancing. One article demonstrated simulations of COVID19 in four different situations: 1) free for all, 2) forced quarantine, 3) social distancing, and 4) extensive social distancing. Out of the four simulations tested, "extensive social distancing," or when only one out of eight people is allowed to continue socializing normally, resulted in the lowest number of sick people and maintained the highest number of healthy people [4]. Extensive social distancing has been shown to decrease the chance of transmitting the virus, which is especially crucial for COVID-19 since not all confirmed cases are symptomatic [5]. A report generated by the Imperial College COVID-19 Response Team states that if no action is taken, 326.079 million people could become infected and 2.981 million people could die in North America. If a suppression strategy, which includes aggressive testing, isolation of all cases, and wider social distancing, is implemented early on, when there are only 0.2 deaths per 100,000 population per week, it would amount to 17.73 million infections and 92,000 deaths in North America. On the other hand, if a similar strategy is implemented but with 1.6 deaths per 100,000 population per week, then there will be 90.529 million infections and 520,000 deaths in North America [6].

Although for many weeks the US had a low number of confirmed cases compared to other countries, this largely seems to be due to under-testing of the virus [7]. Even though the US has six times the population of South Korea, only 103,945 Americans have been tested as of March 19 ${ }^{\text {th }}, 2020$ in contrast to 316,664 South Koreans as of March 20 ${ }^{\text {th }}, 2020$ [8]. One South Korean company, Seegene, initiated making test kits to identify the virus four days before there were any confirmed cases in the country. Eventually, Seegene also developed the ability to provide testing for 1 million patients per week. Usually, it takes about 1.5 years for such testing kits to get approved in South Korea, but for COVID-19, it only took a week for Korea Centers for Disease Control \& Prevention to approve it. South Korea has been providing free and easy access to testing for all of its residents in a timely manner [9]. However, in the US, when the first cases were appearing in Seattle on February $5^{\text {th }}$, the CDC found itself illequipped to deal with the rising demand for the diagnostic test. Due to a lengthy verification process, they only managed to send out a small numbers of tests - many which returned inconclusive by mid-February [10]. Meanwhile, despite this, the FDA prevented private sector companies and foreigndeveloped tests, including the test kit produced by the World Health Organization, from being distributed across the US. It wasn't until February $29^{\text {th }}$ when the CDC opened up testing to private and public sector labs to shorten the length of clinical trials needed for approval [11]. The CDC's mishandling of the diagnostic tests and unnecessary bureaucratic red tape led to American public health experts inability to use tools for contain an early-stage pandemic, such as contact tracing, isolation, individual quarantines and delay in tracking the spread of the disease [10]. Although quickly testing citizens is important, but it is not enough if the test itself has a slow turnaround in a pandemic. To combat this issue, China prepared diagnostic assay tests, which can give results within 4 hours [12]. In the US, COVID-19 test results take 3-4 days to reach the patient. The FDA has recently approved the country's first point-of-care diagnostic test, Xpert ${ }^{\circledR}$ Xpress SARS-CoV-2 test manufactured by Cepheid, that can detect the virus in about 45 minutes. This will help mitigate the current shortage of personal protective equipment and protect healthcare workers and other non-COVID-19 patients from longer exposure to COVID-19 patients spending more time in the waiting areas to get tested [13]. Unfortunately, rural hospitals in the US have been in low supply and have work forces that are stretched thin. Several rural hospitals may be forced to shut down due to lack of revenue from elective procedures, which have been prohibited due to COVID-19. This makes it difficult for rural Americans to access testing even if quicker testing with short turn around time is available [14].

Countries like South Korea and Singapore have effectively limited the spread of COVID-19 and limited the number of 
deaths by enforcing social distancing on a massive scale, cancelling crowded events, quarantining, and closing schools and businesses. By providing testing for all, including the uninsured and the homeless, these countries have managed to protect their population, treat the sick, and collect important data to inform public health policies [15]. The US is only 11 days behind Italy and is on track to repeat such a tragic trajectory. The window for widespread, aggressive action has almost closed [16]. The US must follow the examples of these countries that have controlled the spread of COVID-19 to "flatten the curve" and to avoid overwhelming its healthcare system. When millions of lives are at stake worldwide, it is necessary for countries to share data, learn from mistakes, and act definitively and quickly.

\section{REFERENCES}

1. Lum L and Tambyah P. Outbreak of COVID-19 - an urgent need for good science to silence our fears? Singapore Med J; 2020 61(2): 55-57.

2. Centers for Disease Control and Prevention. Cases in U.S. 2020, Mar 27. Available at

https://www.cdc.gov/coronavirus/2019-ncov/casesupdates/cases-in-us.html (Accessed March 27, 2020)

3. Wujtewicz M, Dylczyk-Sommer A, Aszkiełowicz A, Zdanowski S, Piwowarczyk S, Owczuk R. COVID-19what should anaethesiologists and intensivists know about it?. Anaesthesiol Intensive Ther. 2020; 52(1):34-41.

4. Stevens H. Why outbreaks like coronavirus spread exponentially, and "how to flatten the curve". 2020, Mar 14. Available at https://www.washingtonpost.com/graphics/2020/world/co rona-simulator/ (Accessed March 20, 2020).

5. Some coronavirus patients don't show symptoms. Here's why that's a problem. Advisory Board. 2020, Mar 2. Available at https://www.advisory.com/dailybriefing/2020/03/02/asymptomatic-coronavirus (Accessed March 22, 2020).

6. Walker PGT, Whittaker C, Watson O, Baguelin M, Ainslie KEC, Bhatia S et al. The Global Impact of COVID-19 and Strategies for Mitigation and Suppression. WHO Collaborating Centre for Infectious Disease Modelling, MRC Centre for Global Infectious Disease Analysis, Abdul Latif Jameel Institute for Disease and Emergency Analytics, Imperial College London. 2020, Mar 26. Available at https://www.imperial.ac.uk/media/imperialcollege/medicine/sph/ide/gida-fellowships/ImperialCollege-COVID19-Global-Impact-26-03-2020.pdf (Accessed March 27, 2020)

7. Baker S. The problems with our coronavirus testing are worse than you think. 2020, Mar 16. Available at https://www.axios.com/coronavirus-outbreak-testingdelays-60a25ce6-f08d-438f-b294-358e0c300d95.html (Accessed March 27, 2020).

8. Ortiz-Ospina E and Hasell J. How many tests for COVID19 are being performed around the world? 2020, Mar 20.
Available at https://ourworldindata.org/covid-testing (Accessed March 27, 2020).

9. Watson I, Jeong S, Hollingsworth J, Booth T. How this South Korean company created coronavirus test kits in 3 weeks. 2020, Mar 12. Available at https://www.cnn.com/2020/03/12/asia/coronavirus-southkorea-testing-intl-hnk/ (Accessed March 27, 2020).

10. Baird RP. What Went Wrong with Coronavirus Testing in the U.S. 2020, Mar 16. Available at

https://www.newyorker.com/news/news-desk/what-wentwrong-with-coronavirus-testing-in-the-us (Accessed March 27, 2020).

11. Singer JA. Coronavirus testing delays caused by red tape, bureaucracy and scorn for private companies. 2020, Mar 18. Available at https://www.nbcnews.com/think/opinion/coronavirustesting-delays-caused-red-tape-bureaucracy-scornprivate-companies-ncna1162476 (Accessed March 27, 2020).

12. Cooper R. The Virus That Tells Us Who We Are. Issues in Science and Technology. 2020, Mar 10. Available at https://issues.org/the-virus-that-tells-us-who-we-are/ (Accessed March 28, 2020).

13. FDA News Release. Coronavirus (COVID-19) Update: FDA Issues first Emergency Use Authorization for Point of Care Diagnostic. 2020, Mar 21. Available at https://www.fda.gov/news-events/pressannouncements/coronavirus-covid-19-update-fda-issuesfirst-emergency-use-authorization-point-care-diagnostic (Accessed March 28, 2020).

14. Kaiser Health News. Coronavirus Threatens Rural Hospitals. 2020, Mar 23. Available at https://www.usnews.com/news/healthiestcommunities/articles/2020-03-23/covid-19-threatensrural-hospitals-already-stretched-to-breaking-point (Accessed March 28, 2020).

15. Axios. How to beat back the coronavirus. 2020, Mar 10. Available at https://www.axios.com/how-to-beatcoronavirus-7f38b798-5a11-43c9-a6abe407b2713e44.html (Accessed March 28, 2020).

16. Mahbubani R. The US has one week to enforce social distancing and 'flatten the curve' as the coronavirus outbreak escalates. Here's why these days are so critical. 2020, Mar 17. Available at: https://www.businessinsider.com/us-one-week-enforcesocial-distancing-flatten-curve-coronavirus-2020-3 (Accessed March 28, 2020).

Received: 29 March, 2020 Accepted: 30 March, 2020 *Correspondence to: Isha Patel, $\mathrm{PhD}$ Email: pateli@marshall.edu

Cite article as: Patel I, Goff A, Cho S. The Race against COVID-19 in the US. Res Pharm Healt Sci. 2020;6(1):101-102. doi: https://doi.org/10.32463/RPHS.2019.v06i01.01 